\title{
Improving access to oral healthcare for people experiencing homelessness is good for public health
}

Witton, Robert

http://hdl.handle.net/10026.1/18710

10.1177/1757913920971328

Perspectives in Public Health

SAGE Publications

All content in PEARL is protected by copyright law. Author manuscripts are made available in accordance with publisher policies. Please cite only the published version using the details provided on the item record or document. In the absence of an open licence (e.g. Creative Commons), permissions for further reuse of content should be sought from the publisher or author. 
Improving access to oral healthcare for people experiencing homelessness is good for public health

Authors

Robert Witton ${ }^{1}$, Martha Paisi ${ }^{1,2}$

${ }^{1}$ University of Plymouth Faculty of Health: Medicine, Dentistry and Human Sciences,

Derriford Dental Education Facility, 20 Research Way, Plymouth Science Park, Plymouth,

PL6 8BT

Email: robert.witton@plymouth.ac.uk

Orcid: 0000-0002-6424-4376

2 Peninsula Dental Social Enterprise, Derriford Dental Education Facility, 20 Research Way, Plymouth Science Park, Plymouth, PL6 8BT

Martha Paisi

Email: martha.paisi@plymouth.ac.uk

Orcid: 0000-0001-5718-008X

Corresponding author:

Robert Witton

University of Plymouth Faculty of Health: Medicine, Dentistry and Human Sciences

Derriford Dental Education Facility

20 Research Way

Plymouth Science Park

Plymouth

PL6 8BT 
Homelessness in countries with developed economies remains a significant challenge ${ }^{1}$. In the UK, at least 320,000 people $^{2}$ are currently estimated to live in temporary accommodation or on the streets while an increase in the number of young people and families living in temporary or overnight accommodation has been reported ${ }^{3}$. Homelessness is associated with increased morbidity and mortality ${ }^{2}$. Dental problems are among the most common health concerns affecting people experiencing homelessness, with higher levels of untreated dental disease and more missing teeth than in the general population, causing poorer oral health related quality of life ${ }^{3,4}$. In addition, the lived experience of homelessness and characteristics of the healthcare system contribute to low uptake of dental services ${ }^{5}$

A study in London involving 260 people revealed that $60 \%$ of the participants had suffered from toothache since they became homeless, while $15 \%$ had pulled out their own teeth ${ }^{5}$. A number of organisations have called for better access to oral healthcare for people experiencing homelessness ${ }^{5,6}$ and the NHS Long Term Plan specifically mentions people experiencing homelessness as a priority group ${ }^{7}$. However, despite this there are very few dedicated dental services across the UK that cater for the needs of this group and very little prioritisation for their development. The purpose of this article is to improve awareness of the need to include and integrate oral healthcare into initiatives and programmes that support people experiencing homelessness and explain why doing this is good for public health.

\section{What are the issues?}

People experiencing homelessness can have precarious living conditions making the routine of attending appointments difficult. This effectively excludes them from mainstream high street dental services where dental practices operate as small businesses and rely on regular attendance of patients to maintain financial viability. In addition, some people experiencing homelessness can have high treatment needs and due to its design the current NHS dental contract can disincentive dentists and practices from accepting patients that 
need extensive treatment. In some areas community dental services may accept people experiencing homelessness or there may be ad hoc services offering access, usually for a single course of urgent care only but these are highly variable across the UK making access to care a postcode lottery.

Without access to dental services, the healthcare system is bearing a considerable indirect cost due to attendance at the GP for dental pain and sepsis, inappropriate presentations at A\&E and repeat prescriptions of antibiotics and analgesia by GP outreach services ${ }^{2,5}$. These healthcare costs are avoidable and expensive and often fail to address the dental problem. They also encourage the use of antibiotics for acute dental conditions that often require a surgical intervention to resolve, at a time when anti-microbial resistance is a global public health challenge.

\section{What works?}

Efforts to improve equity in access to oral healthcare for people experiencing homelessness requires significant change in healthcare policy and fundamental change in commissioning philosophy and approach that recognises a 'one size fits all' dental service model does little to address oral health inequalities in this group and in many others. Development of new services should be done in a way that recognises homeless peoples' complex and diverse needs, and is fully integrated into the wider public health and healthcare response to avoid oral health being seen as an optional 'nice to have'.

There is information available in the UK to help in the design of dental services for people experiencing homelessness and a common set of enablers are emerging $8,9,10,12$. Outreach and community engagement can often help to break down barriers to care by meeting people in their own environment, this can help to de-stigmatize the view of healthcare professionals and build positive relationships that are based on trust ${ }^{12}$. The importance of 
community engagement is also increasingly recognised in healthcare education. There is a need to educate the next generation of healthcare professionals to have a greater understanding of the complex circumstances that result in many groups in society experiencing vulnerability and why their access to healthcare services is low ${ }^{13}$. The role of link workers is a key enabler and effective communication and co-ordination between the dental service and the day or residential centre is vital for minimising lost clinical time and encouraging/reminding of attendance. Improving support workers awareness of the importance of oral health can also better support patients' behaviour change journey ${ }^{11,12}$. In terms of the dental service itself, non-judgmental and empathetic staff are integral to facilitating access and a relaxed and friendly atmosphere with good communication and clear expectations for both parties can help to build positive relationships for ongoing care ${ }^{12}$. Perhaps the most important factors are flexibility and personalised care. Being able to respond to patients as individuals is challenging for providers but essential to build a successful service ${ }^{8,9,10,12}$. Providing longer appointments, availability of appointments at short notice and being able to offer appointments to complete treatment in as short a time as possible can all influence service outcomes.

Evidence demonstrates that oral health interventions can improve a homeless person's quality of life and become a significant part of their journey towards stability ${ }^{8,10,12}$. A recent service evaluation of a homelessness dental service in the southwest ${ }^{12}$ reported perceived improvements in oral health measures (oral hygiene), physical health (enhanced nutrition), psycho-social health (improved confidence and self-esteem, happiness and improved body image) and economic impacts (leading to employment, life aspirations and wider engagement with other services). Improving oral health in people experiencing homelessness can be an important catalyst to wider change in multiple areas of a person's life and should be regarded as an essential healthcare need alongside others. 


\section{Conclusion}

Improving access to oral healthcare for people experiencing homelessness is part of the effort to address health inequities and inequalities that exist in the health care system. There is growing evidence in the UK of highly effective models of care that improve access in a way that is acceptable patients and to healthcare professionals. The challenge is to develop flexible commissioning models that address and prioritise the unique oral healthcare needs of this group in a way that is more equitable and sustainable across the UK.

\section{References}

1. Shelter. Far from alone: Homelessness in Britain in 2017. London: Shelter, 2017. Available at

https://england.shelter.org.uk/ data/assets/pdf file/0017/1440053/8112017 Far From Alo ne.pdf (accessed August 2020)

2. NHS. Health Services for Homeless People in London. Case for Action. NHS 2015. Available at: http://www.londonscn.nhs.uk/wp-content/uploads/2015/03/mh-sclg-homeless19062015.pdf (accessed August 2020).

3. Daly B, Newton T, Batchelor P, Jones K. Oral health care needs and oral health-related quality of life (OHIP-14) in homeless people. Community Dent Oral Epidemiol 2010; 38: 136-144.

4. Hill K B, Rimington D. Investigation of the oral health needs for homeless people in specialist units in London, Cardiff, Glasgow and Birmingham. Prim Health Care Res Dev 2011; 12: 135-144.

5. Groundswell. Healthy Mouths: A peer-led health audit on the oral health of people experiencing homelessness. London: Groundswell, 2017. Available at http://groundswell.org.uk/wp-content/uploads/2017/10/Groundswell-Healthy-Mouths-ReportFinal.pdf (accessed August 2020).

6. British Dental Association. Dental Care for Homeless. 2003.

7. NHS. The Long Term Plan. London, NHS. 2019

8. Beaton L, Coles A, Rodriguez A, Freeman R. HoPSCOTCH Report. Homeless People in SCOTland: a process evaluation of a Community-based oral Health intervention - the findings of a pilot study from 4 NHS Boards. Dundee: University of Dundee, 2015.

9. Simons D, Pearson N, Movasaghi Z. Developing dental services for homeless people in East London. Br Dent J 2012; 213: E11 
10. Coles E, Edwards M, Elliot GM, Freeman R, Heffernan A, Moore, A. The Oral Health of Homeless People across Scotland: Report of the Homeless Oral Health Survey in Scotland, 2008-2009. Dundee: University of Dundee, Dental Health Services Research Unit, 2011. 11. Paisi M, Witton R, Allen Z, Plessas A, Withers L, Burrows M, McDonald L, Kay E. Perceived need, dental experiences and factors influencing dental care access for people experiencing homelessness: a qualitative study. Br Dent J 2020 doi: 10.1038/s41415-0201926-7

12. Paisi M, Baines R, Worle C, Withers L, Witton R. Evaluation of a community dental clinic providing care to people experiencing homelessness: A mixed methods approach. Health Expectations 2020 doi: 10.1111/hex.13111

13. Webb L, Sandhu S, Morton L, Witton R, Withers L, Worle C, Paisi M. A dental student view on learning gained through Inter-Professional Engagement with people experiencing homelessness. Education for Primary Care 2019 15, 1-3 